\title{
What Is Responsible for the Fair Process Effect?
}

Kees van den Bos

Utrecht University

Instances of the Fair Process Effect 274

Toward Conceptual Clarity 277

On the Psychology of the Fair Process Effect 282

Instrumental Explanation 283

Social Influence Explanation 284

Referent Cognitions Explanation 285

Relational Explanation 287

Uncertainty Explanation 288

Future Research Directions 292

Conclusions 293 
The present chapter discusses the psychology of the fair process effect, the positive effect that people's fairness perceptions have on their subsequent reactions. After an overview of instances where the effect has been found, definition issues are discussed. These include that the effect can be found on outcome judgments and on other important variables that follow fair and unfair procedures. Furthermore, the effect refers to people's reactions that follow the experience of fair and unfair procedures, and not to the process with which fairness judgments themselves are formed. Moreover, the term fair process should be used in organizational justice to refer to the informal way in which people are treated in decision-making processes, and not to formal procedures. The main part of the chapter discusses psychological explanations of the effect. These include instrumental, social influence, referent cognition, relational, and uncertainty explanations. The chapter concludes with future directions for the study of the fair process effect.

This chapter is about the fair process effect, the positive effect that people's procedural fairness perceptions have on their subsequent reactions (such as satisfaction with outcomes received, acceptance of decisions made by supervisors, protest behavior, and many other important dependent variables). The fair process effect is arguably the most replicated and robust finding in the literature on organizational justice and one of the most frequently observed phenomena and among the basic principles in the organizational behavior and management literature (Greenberg, 2000). Thus, insight into the fair process effect is relevant for all people interested in organizations and organizational behavior and not just for those of us who have specialized in organizational justice. Therefore, this chapter is dedicated solely to this effect. After a short overview of instances where the effect has been found, some definition issues and conceptual problems are identified and dealt with. This is followed by the main part of the chapter, which discusses psychological explanations that have been proposed to explain the effect and its robustness. I conclude with a discussion of future directions that researchers may want to take in studying the fair process effect.

\section{INSTANCES OF THE FAIR PROCESS EFFECT}

In their 1979 article, Folger and his coauthors were the first to coin the term "the fair process effect" (Folger, Rosenfield, Grove, \& Corkran, 
1979). Using a modified version of Hirschman's (1970) conception of voice, Folger et al. reframed the first procedural justice findings reported by Thibaut, Walker, and their colleagues, to suggest that getting the opportunity to present evidence supporting one's own case in a court trial has a strong positive effect on the defendant's reactions toward the verdict (Thibaut \& Walker, 1975, 1978; Walker, LaTour, Lind, \& Thibaut, 1974).

Of the many studies by the Thibaut and Walker group, the experiment conducted by Walker et al. (1974) is widely recognized to be the first procedural justice study that revealed a strong and interesting fair process effect. This experiment set out to investigate the effects of adversary and inquisitorial procedures on the reactions of disputants toward either a favorable or an unfavorable verdict in a simulated court trial. Adversary and inquisitorial procedures may differ on multiple dimensions, but the key distinction that Thibaut and Walker were interested in is that adversary procedures allow people involved in court trials greater levels of control over the process used in the court trial than inquisitorial procedures do. Findings of the Walker et al. study showed that defendants judged the way in which they had been treated to be more fair when they had experienced the adversary procedure than when they had been subjected to the inquisitorial procedure, presumably because the former procedure allowed them greater levels of process control (Thibaut \& Walker, 1975, 1978) and opportunities to voice their opinion (Folger et al., 1979). More important for the current purposes is that the findings also revealed a fair process effect such that participants judged their verdict to be more fair and were more satisfied with the verdict in case of the fair (adversary) procedure as opposed to the unfair (inquisitorial) procedure.

Folger et al. (1979) found a similar fair process effect on overall satisfaction ratings. Folger et al. manipulated, among other things, whether participants in experimental setups either received or did not receive an opportunity to voice their opinions about how the experimenter should divide lottery tickets between participants themselves and the other participants. The most important fair process effect presented in this study was that voice procedures resulted in higher ratings of overall satisfaction than no-voice procedures.

Since these first demonstrations of the fair process effect, many studies have reported comparable effects in many different contexts using different research methods. The effect has been observed most often within the organizational context (Lind \& Van den Bos, 2002) but has frequently been found elsewhere as well (e.g., Paternoster, Brame, Bachman, \& Sherman, 1997; Vermunt, Wit, Van den Bos, \& Lind, 1996). Furthermore, as has been argued by Lind and Tyler (1988), an exciting aspect of research on the effects of procedural fairness perceptions is 
that effects of these perceptions have been found on very different human reactions. This is important because it suggests that fair process studies may have substantial implications for a multitude of domains of human and organizational behavior (Greenberg, 2000).

In organizations, it has been shown that when people feel they have been treated fairly this frequently leads to a variety of positive responses, such as higher commitment to organizations and institutions (Folger \& Konovsky, 1989; Korsgaard, Schweiger, \& Sapienza, 1995; McFarlin \& Sweeney, 1992; Moorman, 1991), more extra-role citizenship behavior (Konovsky \& Folger, 1991; Podsakoff \& MacKenzie, 1993), greater likelihood of conflict prevention and resolution (Bobocel, Agar, Meyer, \& Irving, 1998), better job performance (Lind, Kanfer, \& Earley, 1990), more widespread acceptance of company policy (Greenberg, 1994; Lind, 1990) and supervisor directives ( Huo, Smith, Tyler, \& Lind, 1996), higher levels of job satisfaction (Folger \& Cropanzano, 1998), more positive emotional feelings (Weiss, Suckow, \& Cropanzano, 1999), and increased positive affect and decreased negative affect (Van den Bos, 2001a). People who experience unfair treatment, on the other hand, are more likely to leave their jobs (Alexander \& Ruderman, 1987), are less likely to cooperate (Lind, 2001), show lower levels of morale and higher levels of work stress and overt and covert disobedience (Huo et al., 1996), are more likely to initiate lawsuits (Lind, Greenberg, Scott, \& Welchans, 2000), and may even start behaving in antisocial ways (Greenberg, 1993, 1997; Greenberg \& Lind, 2000).

In contexts other than organizations the fair process effect is similarly overwhelming. For example, the belief that one has been treated fairly by judges, the police, or other social authorities enhances acceptance of legal decisions (Lind, Kulik, Ambrose, \& De Vera Park, 1993), obedience to laws (Tyler, 1990), and evaluations of public policies (Lind, 1990; Tyler, Rasinski, \& McGraw, 1985), whereas the belief that one has been treated unfairly has been shown to prompt protest behavior (Vermunt et al., 1996) and recidivism among spouse abuse defendants (Paternoster et al., 1997).

Fair process effects have been found in laboratory experiments (Folger et al., 1979; Folger, Rosenfield, \& Robinson, 1983; Greenberg, 1987a, 1987b, 1993; Kanfer, Sawyer, Earley, \& Lind, 1987; Lind et al., 1990; Lind, Kurtz, Musante, Walker, \& Thibaut, 1980; Van den Bos, Lind, Vermunt, \& Wilke, 1997; Van den Bos, Vermunt, \& Wilke, 1997; Walker et al., 1974) and in survey studies with respondents involved in settings such as organizations (Folger \& Konovsky, 1989), court trials (Lind et al., 1993; Tyler, 1984), police-citizen encounters (Tyler \& Folger, 1980), and political situations (Tyler \& Caine, 1981, Studies 2 and 4; Tyler \& DeGoey, 1995; Tyler et al., 1985).

Because fair procedures enhance so many important cognitions, feelings, attitudes, and behaviors, insight into what is responsible for the fair 
process effect is crucial for understanding how people think, feel, and behave in their social and organizational environments (Cropanzano \& Folger, 1989, 1991; Cropanzano \& Greenberg, 1997; Greenberg, 2000; Folger \& Konovsky, 1989; Greenberg, 1990, 1993; Lind \& Tyler, 1988; Tyler \& Lind, 1992). To this end, this chapter focuses on the psychology of the fair process effect.

One could well say that the review just presented of the fair process effect suggests that in the organizational justice literature the issue nowadays is not so much whether fair process effects can be found (because the answer is definitely "yes") and not even whether it can be found in a new organizational setting or on a new dependent variable (as research from the 1970s till the new millennium clearly suggests that the answer to this question will be "yes" as well). No, the issue now is, or should be, what is responsible for the fair process effect. Two things are important for this. First, we have to be clear what it is we are talking about when we talk about the fair process effect. Second, in the organizational justice literature it is now time that we start asking and investigating fundamental questions as to the psychology of the effect (Van den Bos, 2001b). This latter issue is the main topic of the current chapter. Before I discuss that subject, a closer look at some important definition and conceptual problems that revolve around the organizational justice literature in general and the fair process effect in particular is in order.

\section{TOWARD CONCEPTUAL CLARITY}

In the organizational justice literature there tends to be some misunderstanding and ambiguity as to how important terms should be understood (cf. Colquitt \& Shaw, this volume). This also applies to the fair process effect and issues that are related to this concept. With respect to the fair process effect, the definition that is used in this chapter is that it refers to the positive effect of people's procedural fairness perceptions on their subsequent reactions.

The studies by Walker et al. (1974) and Folger et al. (1979) became known as showing fair process effects on people's outcome fairness judgments, decision acceptance tendencies, and general satisfaction. These dependent variables obviously are very important. However, this does not imply that fair process effects cannot be found on other human reactions as well. Indeed, what makes the fair process effect so important, and why it is exciting to study the psychology of the effect, is that it has been shown on a huge variety of human responses (Lind \& Tyler, 1988). It would be unwise, therefore, to restrict the label "the fair process effect" only to operationalizations that happen to have been used in the first fair process studies (outcome fairness and satisfaction 
ratings and decision acceptance) and to neglect other important dependent variables.

A precondition before fair process effects can occur is that the experience of a particular procedure leads to the perception of a certain level of procedural fairness. It is this procedural fairness perception that may positively influence the person's later reactions and in this way creates a fair process effect. Thus, for example, when an individual, let's call him Rob, gets an opportunity to voice his opinion about the way in which office space should be allocated in his department, Rob may perceive the way in which he has been treated to be fair. This perception of procedural fairness may then lead Rob to be more satisfied with the final decision of exactly how office space is to be distributed among the staff members. Thus, as is illustrated in Fig. 9.1, the label "the voice effect" should be reserved for the enhancement of procedural fairness when a procedure allows people a chance to express themselves and "the fair process effect" is the enhancement of people's evaluations, attitudes, behaviors, and so on following this procedural fairness perception. Thus, in contrast with what sometimes is done in the literature, a voice effect should not be equated with a fair process effect (Folger et al., 1979). Rather the experience of voice, or encountering an accurate, a consistent, or any other particular procedure (cf. Leventhal, 1980; Van den Bos, Vermunt, \& Wilke, 1996, 1997) will lead to fairness perceptions, and these perceptions should be treated as a prerequisite before fair process effects can be found (see Fig. 9.1). Furthermore, it should be noted here that it is not uncommon to find voice effects that are different (e.g., differentially affected by the experimental manipulations used in the study) from the fair process effects found in the same study (for details, see, e.g., Van den Bos, 2001a; Van den Bos, Maas, Waldring, \& Semin, 2003; Van den Bos \& Miedema, 2000). This suggests that at least sometimes different psychological processes are instigating the two effects.

The previous paragraphs highlighted the importance of perceptions of procedural fairness, and it should be clear what we mean with each of these concepts. The first issue is the role of perceptions in the fair process effect. Numerous authors have stressed that fairness and justice are really in the eye of the beholder (e.g., Adams, 1965; Lind et al., 1990; Mikula \& Wenzel, 2000; Tyler, Boeckmann, Smith, \& Huo, 1997; Van den Bos \& Lind, 2002). It is important to emphasize this once again because there is some tendency in the literature to treat fairness and justice as objective concepts about which there is or may be some objective truth (cf. Hare, 1981; Jasso, 1994, 1999; Rawls, 1971; Sabbagh, Dar, \& Resh, 1994). Rationalist conceptions of fairness and justice are normative and often-but not always (see Haidt, 2001) - philosophical in nature and conceive of justice as predominantly a principle that can be defined in reference to objective standards of right and wrong (Hare, 1981). An ex- 


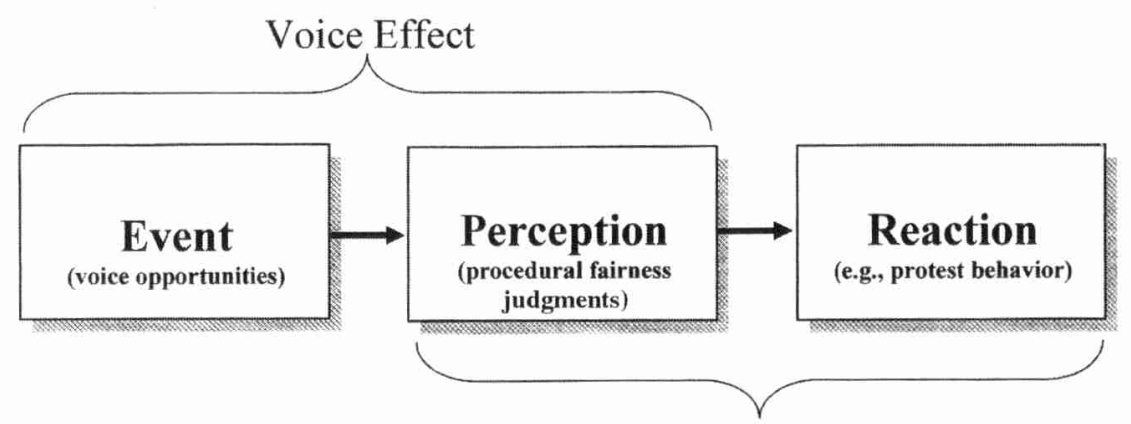

Fair Process Effect

FIG. 9.1. Disentangling the voice effect and the fair process effect.

ample is the work by Jasso $(1994,1999)$ and Sabbagh et al. (1994), who constructed theories in which justice judgments are studied from articulated rational-normative ideas of justice evaluations and justice functions. Although it might be possible to derive rational-normative principles of procedural justice and there hence is the possibility of an objective fair process effect, we should realize that the fair process effect in essence is a psychological effect, constructed in the head of the recipient of the procedure. Thus, psychology of organizational justice and particularly research on the fair process effect should be treated with strong weight to the subjectivity of fairness and justice judgments. This implies that objective conditions that researchers, organizational behaviorists, and employers think are fair or unfair do not have to viewed that way by employees and other lay people.

The second subject is the fairness concept. Compared to the related notions of justice and morality, fairness better connotes the subjective, ready judgment that is and has long been the true topic of psychological study (Van den Bos \& Lind, 2002). Participants and respondents in research studies find it easier and more relevant to provide judgments of fairness than judgments of justice or morality. This is the reason that most psychologists in our field usually ask people to rate fairness rather than to rate justice or morality (cf. Tyler \& Lind, 1992), and this is the rationale for why the central topic of consideration of this chapter is called "the fair process effect" and not "the just process effect" or "the moral process effect." The former simply reflects better both common research practices and the core belief under study. Thus, notwithstanding the fact that organizational psychologists usually call this 
area "organizational justice," we are in effect referring to fairness perceptions as the major antecedent of the effects we are interested in (Lind \& Van den Bos, 2002).

Related to this is the concern of whether what usually is called the fair process effect should be really conceived of as a fair process effect or that it would it be more accurate to start talking about an unfair process effect instead (cf. Greenberg \& Folger, 1983, p. 243). Although the former perspective is in line with how the effect generally is known, the latter view corresponds with notions that have been ventilated (Folger, 1984; see also Brockner \& Wiesenfeld, 1996; Van den Bos \& Spruijt, 2002; Van den Bos \& Van Prooijen, 2001; Van den Bos, Vermunt, \& Wilke, 1997) that we scientists tend to think and talk about the psychology of fairness and justice, whereas unfair events affect lay people's cognitions and reactions stronger than fair events. This finding is probably caused by the important role that people's expectations have in the psychology of fairness judgments (e.g., Van den Bos et al., 1996) and the fact that unfair events may strongly violate these expectations (Van den Bos \& Van Prooijen, 2001). The psychological mechanism behind this finding may well be an instance of the more general negativity effect that indicates that negative things typically have a bigger impact on psychological processes than positive things (see, e.g., Baumeister, Bratslavsky, Finkenauer, \& Vohs, 2001; Fiske \& Taylor, 1991; Peeters \& Czapinski, 1990). All this suggests that unfairness plays a more prominent role and that it might be better to talk about the psychology of injustice as opposed to justice (Folger \& Cropanzano, 1998). Furthermore, it is noteworthy that different theories tend to focus on one of the two effects and in their empirical studies tend to use different dependent variables that are best suited to tap either the fair or the unfair process effect. For example, research studies by the Lind and Tyler group are inclined to focus on the influence perceived procedural fairness may have on people's satisfaction and acceptance of authorities (Lind \& Tyler, 1988; Tyler \& Lind, 1992), whereas Folger and colleagues tend to explore the darker side of the fairness dimension by concentrating on the effects that unfairness may have on resentment and retaliation (e.g., Folger, 1987, 1993; Folger \& Baron, 1996; Folger \& Skarlicki, 1998). In this chapter, I use the traditional term "the fair process effect," with the understanding that, unless explicitly stated otherwise, this may involve the effects of both fair and unfair procedures on people's reactions.

The final issue that I want to put forward here is what we mean with procedure. The name is derived from the law literature and especially from the title of the 1975 book by social psychologist John Thibaut and law professor Lawrence Walker. These authors and their associates were inspired by the psychological differences they saw between different legal procedures, and in their pioneering procedural justice experi- 
ments they took these differences as starting point for their investigation of participants' reactions toward procedures that varied the amount of process control that participants experienced in simulated court trials. Thus, Thibaut and Walker combined their mutual interests in social psychology and law and as a result they placed their studies under the heading of "procedural justice" research. However, this should not be taken too literally, because these authors clearly saw their experiments as a first step toward understanding the psychology involved in fairness and justice issues (Thibaut \& Walker, 1978) and were intrigued by the implication of their findings that how people are treated in courts of law can have strong impact on their reactions to judges' verdicts (Walker et al., 1974).

Following this pioneering research, scientists have deepened our understanding of the psychological processes hinted at in the Thibaut and Walker work (e.g., Folger et al., 1979; Folger, 1986; Greenberg, 2000; Greenberg \& Folger, 1983; Lind \& Tyler, 1988; Tyler \& Lind, 1992; Van den Bos \& Lind, 2002) and rightfully noted that the psychological processes involved in the Thibaut and Walker simulations could be adequately expanded to incorporate how people react to fairness and justice in other contexts than legal settings. Most notably, the role of procedural justice in the workplace was recognized to be very important (Colquitt, Conlon, Wesson, Porter, \& Ng, 2001; Greenberg, 2000; Greenberg \& Folger, 1983; Lind \& Tyler, 1988) and, in fact, nowadays the organizational context is the setting in which the fair process effect has been most widely studied. Furthermore, during the 1975-1985 advancement of research and theory on procedural justice it became clear that what by then had became known as procedural justice effects were really effects of how fairly people felt they had been treated in the particular context under investigation (for an overview, see, e.g., Lind \& Tyler, 1988).

In correspondence with this, the fair process effect research that is reviewed in this chapter is about the effect of the fairness of the way in which people feel they have been treated in the workplace or elsewhere. Thus, procedural fairness and justice as they are being used here, and as I think that John Thibaut really intended them to be, refer to the way people are treated. So, in essence, fair or unfair treatment in interpersonal and social interactions is the issue here.

It is important to note that this conception of procedural justice overlaps closely (but see Bies, this volume) with a notion that was developed later in the organizational justice literature, the concept of "interactional justice" (see Bies \& Moag, 1986; Bies \& Shapiro, 1987). One could argue that a danger of using the procedural justice label is that it may be a bit of a misnomer and that people may wrongfully misinterpret the concept to mean to refer to formal, lawlike procedures. The interactional justice label has as an advantage that it clearly refers to the 
justice and fairness aspects of social interactions that are so important in understanding the majority of the fairness effects reported in the psychological literature. Its main disadvantage, however, is that when, in addition to the two earlier developed notions of distributive and procedural justice, researchers start using this concept they have to redefine the concept of procedural justice. That is, because of the obvious overlap of interactional justice with informal procedural justice (Tyler \& Bies, 1990; but see Bies, this volume), introducing the concept of interactional justice forces researchers to start redefining procedural justice in terms of formal decision-making procedures. In the modern organizational justice literature there is a strong tendency to do this. However, as mentioned before, this formal aspect was never meant to be important in the work by the founders of procedural justice. On the contrary, they were really referring to the more informal way in which people were treated in decision-making processes. It is this latter conception, the fairness of informal treatment, that I think the literature should focus on (for a similar argument, see Tyler \& Bies, 1990), and I refer to this by means of the notions that were originally developed for these effects: procedural justice (Thibaut \& Walker, 1975) and the fair process effect (Folger et al., 1979). Treating these concepts in a formal, as opposed to an informal, way would be a major error.

\section{ON THE PSYCHOLOGY OF THE FAIR PROCESS EFFECT}

Now that we have reviewed studies that have shown the fair process effect and have defined the central topics of this chapter, it is time to start exploring the psychology of the effect. It should be noted here that I discuss some explanations that were developed, and review research studies that were conducted to understand not only the fair process effect but other fairness issues as well. The fair process implications of these accounts are reviewed here, with broader implications of the research studies mentioned when appropriate. For fairness theories that are important to understand the procedural justice concept but that are less directly related to the psychology of the fair process effect, the reader is referred to other chapters of this handbook (see especially the chapter by Brockner and the chapter by Cropanzano \& Ambrose). Furthermore, it is important to note here that whether fair process effects have been reported on outcome judgments, satisfaction ratings, stealing behavior, or whatever other dependent variable was used in a particular fair process study does not bother us so much in this chapter as does the psychology of what these effects have in common. For discussion of the effects of perceived procedural fairness on specific dependent variables, please see the chapters by Conlon, Tyler, Moorman, and Vermunt and Steensma in this volume. 
I start by reviewing the oldest explanations of the fair process effect first. After having discussed theories that have been developed later, I note some future avenues research on the psychology of the effect may want to take in the conclusion section that follows this discussion of the psychology of the fair process effect.

\section{Instrumental Explanation}

Thibaut and Walker (1978; Walker, Lind, \& Thibaut, 1979) were the first to construct a general theory of procedural fairness, with special attention to the fairness of disputes dealt with in the legal process. Their theory of procedure applied theories and methods of social psychology to examine and compare various procedural systems incorporated in the legal process and attempted to explain what is responsible for the effects of perceived procedural fairness on human reactions to these procedures and their outcomes.

These authors' analysis of the findings of the Walker et al. (1974) experiment and related studies emphasizes the amount of control allocated to disputants (cf. Shapiro, this volume). Thibaut, Walker, and their colleagues postulated that the distribution of control among disputants involved in a legal process is the most significant factor in characterizing a procedural system and that all changes in procedure may be measured according to their effects on this central control relationship. Two types of control were distinguished: control over the decision and control over the process. A disputant's amount of decision control is the degree to which the disputant may unilaterally determine the outcome of the dispute. Control over the process refers to control over the development and selection of information that will constitute the basis for resolving the dispute. The allocation of process and decision control determines the overall distribution of control among the disputants involved and it therefore, according to Thibaut and Walker (1978), determines the essential character of procedures. Because adversary and inquisitorial procedures differ in the amount of process control given to disputants, with adversary procedures yielding higher levels of process control, this explained, according to Thibaut and Walker $(1975,1978)$, why their participants judged the former type of procedure to be more fair and reacted more favorably toward the verdict resulting from the procedure.

Thibaut and Walker's working hypothesis was that legal conflicts are predominantly disagreements about the apportoinment of outcomes, such as conflicts of interests and disputes about inconsistent claims to the division of assets or losses, and that these arguments about the division of outcomes are hence best resolved with the aim of achieving distributive justice. These authors, therefore, saw the appropriate goal of 
legal procedures to be the achievement of distributive justice (Thibaut \& Walker, 1978). The Thibaut and Walker theory thus suggested that people want to have control over the decision or over the processes that lead to the outcome decision so that they can make sure that the ultimate outcome is fair. This instrumental focus implied that they proposed that people attach more weight toward decision control than process control and that their explanation of the fair process effect is more focused on outcome considerations of fairness judgments than later developed accounts are. It is important to note here, however, that an important aspect of the Thibaut and Walker $(1975,1978)$ model was the focus on whether people received fair outcomes and not so much on how favorable outcomes were to people (Van den Bos \& Lind, 2002). It is therefore more appropriate to label these authors' theory as the "instrumental model," and I think it is wrong to call this the "self-interest model," as is often done in the literature. Using the latter label would easily lead one to conclude, as one sometimes sees in the literature, that Thibaut and Walker conceived of human beings as utterly self-centered and selfish creatures, which I think is an overstatement and is not how these authors conceived of people.

\section{Social Influence Explanation}

Greenberg and Folger (1983) were the first to explicitly position the fair process effect in organizational contexts and were also the first to review different explanations of the psychology of the effect. To this end they noted that what is responsible for findings by Thibaut and Walker (1975; Walker et al., 1974) could be either more positive human reactions because of the experience of a fair process (i.e., a fair process effect) or more negative reactions when the freedom to exercise voice has been denied or when other unfair procedures have been experienced (i.e., an unfair process effect). Greenberg and Folger explained the occurrence of these fair and unfair process effects by pointing to the role of effectance (White, 1959) and reactance (Brehm, 1966) motives, respectively. Because effectance is relevant only to positive effects of perceived procedural fairness and reactance is restricted to unfair process effects, both effectance and reactance accounts are limited in their ability to explain the effects of reactions to variations in procedural fairness (Greenberg \& Folger, 1983).

A third explanation by Greenberg and Folger (1983), and this is probably their best known account of the fair process effect, points at social influence processes as an important psychological mechanism. This explanation holds that the fair process effect can be explained in terms of people being susceptible to influence via social comparison of others' opinions about whether certain outcome distributions are equitable or 
inequitable. Evidence for this line of reasoning was reported by Folger et al. (1979), who predicted and found that the exercise of voice should lead to more positive responses when people do not receive explicit feedback from others supporting their own opinion that the decision was unfair. However, when people receive information from others that confirm their beliefs and indicates that the final decision was inequitable, then voice opportunities may not lead to a fair process effect. The experiments conducted by Folger et al. (1979) and the line of reasoning put forward in Greenberg and Folger (1983) thus suggest that an important psychological mechanism germane to the fair process effect is a social influence explanation.

\section{Referent Cognition Explanation}

Referent cognitions theory, another line of work instigated by Rob Folger, constitutes a different explanation of the fair process effect. In the course of time, different versions of the framework have been developed (for overviews, see Cropanzano \& Folger, 1989; Folger, 1986, 1987, 1993; see also Folger \& Cropanzano, 1998), but these versions all share an important core principle as to the psychology of fairness issues. With respect to the fair process effect, the theory argues that people's reactions to procedural justice depend largely on their counterfactual thoughts (Kahneman \& Tversky, 1982). In essence, referent cognitions theory reasons that when a procedural rule is broken people's thinking becomes inherently referential: People use a frame of reference for evaluating what happened that consists of a mental comparison to what might have happened instead (see also Van den Bos et al., 1996; Van den Bos, Lind, Vermunt, \& Wilke, 1997).

In classic referent cognitions studies (Cropanzano \& Folger, 1989; Folger \& Martin, 1986; Folger et al., 1983), all participants failed to obtain a bonus of extra course credit. Participants in the high referent outcome conditions were led to believe that there was an alternative situation in which they would have received the bonus. Participants in the low referent outcome conditions were informed that they would not have obtained the bonus in either case. The manipulation of procedure in the studies by Folger and Martin (1986) and Folger et al. (1983) varied whether participants were given good reasons (high-justification conditions) or poor reasons (low-justification conditions) why they failed to obtain the bonus. The procedure manipulation in the experiment by Cropanzano and Folger (1989) was such that participants got (participant-decision condition) versus did not get (experimenter-decision condition) to decide which of two types of tasks would be the task with which-depending on their performance on the task-they would have an opportunity to obtain the bonus. Findings of these studies indicated 
that participants showed the highest levels resentment and discontent when high referent outcomes were combined with bad procedures.

Van den Bos and Van Prooijen (2001) recently resolved some important methodological problems in the earlier referent cognitions studies and showed that people react more strongly to voice versus no-voice procedures when reference points are close as opposed to distant. Participants in one of the Van den Bos and Van Prooijen experiments read and responded to stimulus information manipulated by means of scenarios. In these scenarios, participants were asked to imagine that they were a member of a group of people (the blue team). Participants in the voice condition were informed that members of the blue team received an opportunity to voice their opinions about a decision that had to be made, and participants in the no-voice condition were told that members of the blue team did not receive such an opportunity. By means of the reference point manipulation, we made it easier for participants in the close reference point condition to imagine that something else could have happened than for those in the distant reference point condition: In the close reference point condition, we informed participants that they had until recently been a member of a different group (the red team). In the distant reference point condition, participants were not told that they had been a member of a different team. Following the line of reasoning already presented, we argued that when a clear alternative situation is available (still being a member of the red team) it would be easier for participants to imagine that something else could have happened (if only they would still have been a member of the red team) than in the distant reference point condition (where there is no alternative previous group membership). As a consequence, following referent cognitions theory, we predicted that stronger fair process effects would be found in the close reference point condition than in the distant reference point condition.

Results indeed showed that when it was easier for participants to imagine that something else could have happened (because they had until recently been a member of a different group), their reactions indicated stronger fair process effects than when it was less easy to imagine something else could have happened (because there was no previous group). In other words, when people are confronted with a close reference point their reactions show stronger fair process effects than participants who have been subjected to a distant reference point.

These findings provide supportive evidence for the explanation that referent cognitions play a crucial role in understanding the psychology of the fair process effect. Furthermore, because the referent cognitions explanation argues that particularly when a fairness rule is broken people's thinking becomes inherently referential, and because counterfactual thinking is stronger when people have received nega- 
tive as opposed to positive information (e.g., Landman, 1987; Zeelenberg, Van den Bos, Van Dijk, \& Pieters, 2002), we reasoned that especially in the no-voice conditions participants' reactions would be affected by their referent cognitions. The findings reported in the Van den Bos and Van Prooijen (2001) article are in correspondence with this in that effects of closeness of reference points on people's reactions were predominantly found in the no-voice conditions and not in the voice conditions. This result suggests that referent cognitions are affecting human reactions more strongly following the experience of unfair procedures, and this may well imply that the referent cognitions explanation is particularly well suited to account for the psychology of the unfair process effect.

\section{Relational Explanation}

The relational model of authority (Tyler \& Lind, 1992) and the associated group-value model (Lind \& Tyler, 1988) are broad models of procedural justice and attempt to explain more than only the fair process effect. The core message is that "what makes people tick," what makes them respond so strongly toward perceptions of fair and unfair procedure, is the fact that people are primarily concerned about their longterm relationship to the authorities, institutions, or groups that employ the procedures. Reactions toward fair and unfair treatment by authorities and others therefore depend on the implications of the relational treatment for feelings of self-worth and for the belief that the group is functioning properly and fairly.

The relational explanation of the fair process effect argues that, in comparison with an outcome, a procedure reveals more relational information about what an authority thinks about the recipient of the procedure: Does the authority trust me, am I treated in a neutral manner, am I accorded the appropriate standing, and am I included in the group, organization, or society in question? The relational account thus states that people often think procedural information is especially diagnostic with respect to their inclusion in the group or organization, and they reciprocate this message of belongingness by being more accepting of less than ideal outcomes.

Several research studies have been carried out to test implications of the relational explanation (see, e.g., Smith \& Tyler, 1997; Smith, Tyler, Huo, Ortiz, \& Lind, 1998; Tyler, 1990, 1991, 1994, 1997; Tyler \& DeGoey, 1995; Tyler, DeGoey, \& Smith, 1996; Tyler \& Lind, 1990). Research by Huo et al. (1996) shows that, as the explanation predicts, procedure treatment evaluations have a greater impact on distributive fairness judgments in intragroup settings, where inclusion is presumably a more potent consideration, than in intergroup settings. 
Building on the relational model, Van Prooijen, Van den Bos, and Wilke (2002) recently focused on the role of status as antecedent of fair process effects. Their analysis of the relational explanation led these authors to propose that salience of the general concept status should lead people be more attentive to procedural fairness information and that, as a result, their reactions should show stronger fair process effects. Findings of two experiments indeed showed more compelling fair process effects in status-salient than in status-nonsalient conditions. Further evidence for the relational explanation was found by means of a wordfragment completion task in which participants were presented with uncompleted words that could either be completed as fairness-related or non-fairness-related words. Results of the cognitive activation data thus obtained showed that status salience led to increased accessibility of fairness concerns. In line with the relational explanation, this suggests that following salience of important relational elements, such as status issues, people start becoming more attentive to fairness information and that as a consequence their reactions are more strongly affected by perceived procedural fairness

The relational explanation postulates a value-expressive component to underlie the fair process effects that follow from getting voice, and, in accordance with this perspective, research findings by Lind et al. (1990) indeed reveal that, when given an opportunity to voice their opinions after outcome decisions have been made, perceived procedural fairness may positively affects people's reactions, presumably because of the value-expressive and not a self-interest component. In further correspondence with the relational explanation, Tyler (1987) shows that a key precondition for value-expressive effects to occur are individuals' beliefs that the authorities involved have considered their views. This effect of due consideration is supportive for Tyler and Lind's hypothesis that fairness of relational treatment is what is responsible for the fair process effect. What is noteworthy, I think, is that the strong emphasis on relational treatment issues in the relational model overlaps closely with the concept of interactional justice (Bies \& Moag, 1986; Bies \& Shapiro, 1987), suggesting that the relational explanation and work on interactional justice are more similar than is often thought. (For an alternative perspective on this issue, please see Bies, this volume.)

\section{Uncertainty Explanation}

The final explanation that I would like to review here states that uncertainty is playing a major role in the psychology of the fair process effect (Van den Bos, 2001a; Van den Bos \& Lind, 2002). Although the earlier reviewed explanations (Folger, 1986; Greenberg \& Folger, 1983; Thibaut \& Walker, 1978; Tyler \& Lind, 1992) all acknowledged at some point that 
uncertainty may be important, the uncertainty explanation discusses this more explicitly and thoroughly.

The uncertainty explanation developed out of research that was conducted following the fairness heuristic framework (see Lind, 2001; Van den Bos, 2001c; Van den Bos, Lind, \& Wilke, 2001) at the end of the 1990s and the beginning of the new millennium. By then, strong fair process effects had been found so frequently in research studies that the effect was probably the most important factor that led a number of procedural justice researchers to conclude that the formation of overall fairness judgments is more strongly affected by procedures than by outcomes (see, e.g., Lind \& Tyler, 1988, p. 1). This led to the situation that procedural justice research tended to focus on one aspect of the psychological process leading to fairness perceptions and subsequent reactions: procedures. Distributive justice researchers, on the other hand, also were inclined to focus on one aspect of the fairness judgment process: outcomes. Some distributive researchers even suggested that outcomes may be more important for understanding fairness judgments and human reactions than procedures (e.g., Lerner \& Whitehead, 1980; Rutte \& Messick, 1995). Thus, both procedural and distributive justice research tended to focus on only one aspect of the fairness judgment process, at the expense of other important concepts. As several authors noted at that time, it was time to integrate the procedural and distributive justice domains (Brockner \& Wiesenfeld, 1996; Cropanzano \& Folger, 1991; Folger, 1984; Greenberg, 1986, 1990; Sweeney \& McFarlin, 1993; Tyler, 1994; Van den Bos, Vermunt, \& Wilke, 1997).

To this end, my colleagues and I started exploring the psychology of the classical case of the fair process effect, the occurrence of the effect on outcome fairness judgments, and we began wondering how people in effect form evaluations of outcome fairness (Van den Bos, Lind, Vermunt, \& Wilke, 1997). We noted that probably the most well-known and the most widely accepted answer to the question of how people decide whether their outcome is fair or unfair has been provided by equity theory (e.g., Adams, 1965; Walster, Berscheid, \& Walster, 1973; Walster, Walster, \& Berscheid, 1978). In essence, equity theory proposes that people judge an outcome as fair when their own outcome-to-input ratio equals some comparative or referent outcome-to-input ratio. This process is often driven by social comparison with other people's outcomes and inputs such that people judge their outcome as fair when the ratio of their own inputs and outcomes equals the ratio of inputs and outcomes of comparison others (Messick \& Sentis, 1983). Equity theory and other related conceptions of justice-such as relative deprivation theory (Crosby, 1976; Stouffer, Suchman, DeVinney, Star, \& Williams, 1949) and the distributive justice conceptions of Blau (1964), Deutsch $(1975,1985)$, and Homans (1961) - all emphasize the importance of social compari- 
son information in the process of evaluating outcomes. As Messick and Sentis (1983) noted, a central theme in the literature on outcome fairness is that the comparison of a person's outcome with those of comparison others influences the person's beliefs about the fairness or justice of his or her own outcome.

Equity theory has received wide support in social and organizational studies and has been very influential. But as we noted in the 1997 paper, one of its basic propositions is that, in order to judge whether an outcome is fair, people have to know what outcomes comparison others have received. The Van den Bos, Lind, Vermunt, and Wilke (1997) article began by asking whether people always know the outcomes of others, as most theorizing on equity theory assumes they do. We argued that they frequently do not. For instance, in everyday life we often do not know the salaries of the people with whom we work, and even if we do, we may not have a good idea of their contributions. If, as we believed, social comparison information about outcomes frequently is not available, then in everyday life the issue of how people form judgments of outcome fairness is more complicated than equity theory suggests.

Using this reasoning led us to predict fair process effects on people's outcome judgments: We proposed that when information about outcomes of others is not available, people would start using other fairness-relevant information that is available. But what information is available? We suggested that procedural information is frequently present, even in situations where others' outcomes or contributions are unknown. Thus, in many situations people may turn to the fairness of procedures to determine how to judge their outcome, using procedural fairness as a heuristic substitute to judge the fairness of their outcome. Therefore, in situations where a person only knows his or her own outcome but not other equity-relevant information, we predicted a fair process effect: People would judge their outcome to be more fair following a fair rather than an unfair procedure.

However, we also reasoned that when a person does have enough information to form an equity judgment-when, for example, information is available about the outcome of a comparable other person-the person making the fairness judgment will use this social comparison information as a basis for forming outcome fairness judgments. Therefore, we expected less strong fair process effects in situations where a person knows what outcome the referent other received. When people had social comparison information about outcomes there would be less need for procedural fairness to serve as a heuristic substitute in the process of forming judgments of outcome fairness.

The results of Van den Bos, Lind, Vermunt, and Wilke (1997) strongly support this line of reasoning and suggest that when people are uncertain about outcomes of social comparison others they indeed use proce- 
dural fairness - as a heuristic substitute-to assess how to react to their own outcome (yielding fair process effects on people's judgments of outcome fairness). But people rely less on procedure information when they are certain about the outcome received by comparison others (resulting in weak or nonsignificant fair process effects). This shows that, to understand the fairness process effect, it is important to take into account conditions of information certainty or uncertainty.

The uncertainty explanation suggests an interesting implication of the fact that fair process effects on outcome fairness evaluations have been so frequently found: Apparently people are very often uncertain about how to evaluate the fairness of the outcomes they have received, and it is under these conditions of uncertainty about outcome fairness that procedural fairness perceptions start kicking in on people's evaluations of outcome, yielding strong fair process effects on their outcome judgments (Van den Bos, 2001a; Van den Bos et al., 2001). This suggests that the fair process effect is so omnipresent and profound because often, perhaps typically, people are reacting in the way they do because they are uncertain about the things they are reacting to.

In a later paper (Van den Bos, Wilke, Lind, \& Vermunt, 1998) we expanded on the 1997 findings and showed that fair process effects occur not just when perceivers lack strong social comparison information of the sort present in the other-outcome-known conditions of the Van den Bos, Lind, Vermunt, and Wilke (1997) studies: In other situations where it is reasonable to suppose that perceivers are uncertain about important elements needed to judge outcome fairness, they rely more strongly on procedure information in the process of judging outcome fairness, and hence their outcome fairness judgments are more strongly affected by procedure information (see Van den Bos, Wilke, Lind, \& Vermunt, 1998).

Skitka (2002) also reported similar findings as the Van den Bos, Lind, Vermunt, and Wilke (1997) study using a different operationalization of outcome certainty. In the Van den Bos, Lind, Vermunt, and Wilke experiments, certainty about outcome fairness was manipulated by giving participants either complete or incomplete information about social comparison-based equity. Skitka has found comparable effects by making a distinction between situations in which people have a very clear a priori sense of fair outcomes (a moral mandate) and situations in which they do not have a strong moral mandate. Her findings showed stronger fair process effects on outcome evaluations among respondents who did not have a clear a priori sense of what outcomes are fair or unfair than among those who did have strong moral mandates.

At the beginning of the new millennium, the earlier fairness heuristic studies were expanded to a more broader uncertainty management framework (Van den Bos, 2001a; Van den Bos \& Lind, 2002). We argued that heuristic processes are a special case of how people deal with un- 
certainty and we argued more explicitly that uncertainty is a crucial assumption in the psychology of the fair process effect in organizations (Lind \& Van den Bos, 2002) and elsewhere (Van den Bos \& Lind, 2002). Reason for this expansion were research findings that showed strong fair process effects when people were uncertain about authority's trustworthiness in controlled settings (Van den Bos, Wilke, \& Lind, 1998) or in organizational contexts (Van den Bos, Van Schie, \& Colenberg, 2002) or when issues related to uncertainty (Van den Bos, 2001d; Van den Bos \& Miedema, 2000) or general self-related uncertainty were salient (Van den Bos, 2001a). All these findings converge on the same point that strong fair process effects are more likely to be found in uncertain circumstances and that people have a greater interest in fairness in uncertain as opposed to certain situations.

An ironic implication of the uncertainty explanation should be noted here: After having discovered the first instances of the fair process effect, organizational researchers set out to test the effect in what was thought of then as especially difficult circumstances for the effect to occur: The effect was tested in settings where respondents were laid off, where reorganization processes were going on, and so on (for an overview, see Lind \& Tyler, 1988; see also Brockner, 1990, 1994; Brockner, Grover, Reed, DeWitt, \& O'Malley, 1987). Organizational justice researchers were quite pleased to find strong fair process effects under these harsh conditions. The uncertainty explanation, however, points out that it is not so surprising to find the effects there, but that fair process effects are especially likely to be found in these kind of uncertain situations.

Another reason why the uncertainty explanation may be important for organizational researchers is that it contradicts economic perspectives on organizational behavior and managerial practice, which tend to think of organizational justice as some luxurious good, to be awarded to employees in quite times. The uncertainty analysis, however, suggests that it is especially in times of turmoil that organizational justice is important (Lind \& Van den Bos, 2002; Van den Bos, Heuven, Burger, \& Fernández van Veldhuizen, in press).

\section{FUTURE RESEARCH DIRECTIONS}

Future research may want to investigate the psychological mechanisms proposed by these explanations more thoroughly and deeply than has done before and possibly may want to explore the relative explanatory power of these mechanisms. I hasten to note here that because the fair process effect involves such a wide variety of specific procedures, contexts, and types of human reactions, it could well be that it would turn out to be a wrong and an inefficient research strategy to try to set up a 
crucial experiment, aimed at proving that one mechanism can provide a complete explanation (Greenberg \& Folger, 1983). The different explanations of the fair process effect that have been put forward in the literature may suggest that various important motives and processes are underlying the effect (cf. Van den Bos, 2002; Van Prooijen, Van den Bos, \& Wilke, in press), and it may well be that it turns out to be better and wiser to start investigating the specifics of the psychological mechanisms proposed in the literature and to begin focusing on the differences between the various procedures, conditions, and dependent variables (see, e.g., Folger \& Konovsky, 1992; Sweeney \& McFarlin, 1993).

In developing new research, organizational psychologists may want to realize that the field is now waiting for answers to fundamental questions and hence that it is now time to start conducting fundamental research on the psychology of the fair process effect and other organizational justice phenomena. Going back to the roots from which research on the fair process effect has developed (Folger et al., 1979; Walker et al., 1974) may be extremely conducive in this respect, as using the basic theories, thorough research methods, and ingenious process measures of social psychology (see, e.g., Hafer, 2000; Steiner, Guirard, \& Baccino, 1999; Van den Bos \& Van Prooijen, 2001; Van Prooijen et al., 2002) may make it possible to understand the fundamentals of organizational justice issues. It is my hope that this chapter may contribute to these and other future avenues of research on the psychology of the fair process effect in the workplace and elsewhere.

\section{CONCLUSIONS}

In this chapter we have seen that the fair process effect is alive and well and that several explanations of the psychology of the effect have been put forward. What I personally find interesting, at the risk of blowing my own horn, is that in all explanations reviewed here uncertainty plays an important role, perhaps suggesting that the uncertainty explanation is best able to integrate the different explanations and may provide the broadest and most accurate explanation of the fair process effect in most (but in all likelihood not all) instances. What we further have seen in this chapter is that the fair process effect, and the varying perspectives on the effect that have been reviewed here, may well serve as a common thread for organizing key contributions to the literature on organizational justice. This implies that the fair process effect may nicely be used as an organizational schema that ties together many seemingly disparate approaches to the justice field. This alone makes the fair process effect very important and exciting to study. 


\section{ACKNOWLEDGMENT}

I thank Jerry Greenberg for his comments on a previous version of this chapter.

\section{REFERENCES}

Adams, J. S. (1965). Inequity in social exchange. In L. Berkowitz (Ed.), Advances in experimental social psychology (Vol. 2, pp. 267-299). New York: Academic Press.

Alexander, S., \& Ruderman, M. (1987). The role of procedural and distributive justice in organizational behavior. Social Justice Research, 1, 117-198.

Baumeister, R. F., Bratslavsky, E., Finkenauer, C., \& Vohs, K. D. (2001). Bad is stronger than good. Review of General Psychology, 5, 323-370.

Bies, R. J., \& Moag, J. S. (1986). Interactional justice: Communication criteria of fairness. In R. Lewicki, B. H. Sheppard, \& M. H. Bazerman (Eds.), Research on negotiation in organizations (pp. 43-55). Greenwich, CT: JAI.

Bies, R. J., \& Shapiro, D. L. (1987). Interactional fairness judgments: The influence of causal accounts. Social Justice Research, 1, 199-218.

Blau, P. M. (1964). Exchange and power in social life. New York: Wiley.

Bobocel, D. R., Agar, S. E., Meyer, J. P., \& Irving, P. G. (1998). Managerial accounts and fairness perceptions in conflict resolution: Differentiating the effects of minimizing responsibility and providing justification. Basic and Applied Social Psychology, 20, 133-143.

Brehm, J. W. (1966). A theory of psychological reactance. New York: Academic Press.

Brockner, J. (1990). Scope of justice in the workplace: How survivors react to coworker layoffs. Journal of Social Issues, 46, 95-106.

Brockner, J. (1994). Perceived fairness and survivors' reactions to layoffs, or how downsizing organizations can do well by doing good. Social Justice Research, 7, 345-363.

Brockner, J., Grover, S., Reed, T., DeWitt, R., \& O'Malley, M. (1987). Survivors' reactions to layoffs: We get by with a little help from our friends. Administrative Science Quarterly, 32, 526-541.

Brockner, J., \& Wiesenfeld, B. M. (1996). An integrative framework for explaining reactions to decisions: Interactive effects of outcomes and procedures. Psychological Bulletin, 120, 189-208.

Colquitt, J. A., Conlon, D. E., Wesson, M. W., Porter, C. O. L. H., \& Ng, K. Y. (2001). Justice at the millennium: A meta-analytic review of 25 years of organizational justice research. Journal of Applied Psychology, 86, 425-445.

Cropanzano, R., \& Folger, R. (1989). Referent cognitions and task decision autonomy: Beyond equity theory. Journal of Applied Psychology, 74, 293-299.

Cropanzano, R., \& Folger, R. (1991). Procedural justice and worker motivation. In R. M. Steers \& L. W. Porter (Eds.), Motivation and work behavior (Vol. 5, pp. 131-143). New York: McGraw-Hill.

Cropanzano, R., \& Greenberg, J. (1997). Progress in organizational justice: Tunneling through the maze. In C. L. Cooper \& I. T. Robertson (Eds.), International review of industrial and organizational psychology (pp. 317-372). New York: Wiley.

Crosby, F. (1976). A model of egoistical relative deprivation. Psychological Review, 83, 85-112. 
Deutsch, M. (1975). Equity, equality, or need? What determines which value will be used as the basis of distributive justice? Journal of Social Issues, 31, 137-149.

Deutsch, M. (1985). Distributive justice: A social psychological perspective. New Haven, CT: Yale University Press.

Fiske, S. T., \& Taylor, S. E. (1991). Social cognition (2nd ed.). New York: McGraw-Hill.

Folger, R. (1984). Preface. In R. Folger (Ed.), The sense of injustice: Social psychological perspectives (pp. ix-x). New York: Plenum.

Folger, R. (1986). Rethinking equity theory: A referent cognitions model. In H. M. Bierhoff, R. L. Cohen, \& J. Greenberg (Eds.), Justice in social relations (pp. 145-162). New York: Plenum.

Folger, R. (1987). Reformulating the preconditions of resentment: A referent cognitions model. In J. C. Masters \& W. P. Smith (Eds.), Social comparison, social justice, and relative deprivation: Theoretical, empirical, and policy perspectives (pp. 183-215). Hillsdale, NJ: Lawrence Erlbaum Associates.

Folger, R. (1993). Reactions to mistreatment at work. In K. Murnigham (Ed.), Social psychology in organizations: Advances in theory and research (pp. 161-183). Stanford, CA: Stanford University Press.

Folger, R., \& Baron, R. A. (1996). Violence and hostility at work: A model of reactions to perceived injustice. In G. R. VandenBos \& E. Q. Bulatao (Eds.), Violence on the job: Identifying risks and developing solutions (pp. 51-85). Washington, DC: American Psychological Association.

Folger, R., \& Cropanzano, R. (1998). Organizational justice and human resource management. Thousand Oaks, CA: Sage.

Folger, R., \& Konovsky, M. (1989). Effects of procedural and distributive justice on reactions to pay raise decisions. Academy of Management Journal, 32, 115-130.

Folger, R., \& Martin, C. (1986). Relative deprivation and referent cognitions: Distributive and procedural justice effects. Journal of Experimental Social Psychology, 22, 531-546.

Folger, R., Rosenfield, D., Grove, J., \& Corkran, L. (1979). Effects of "voice" and peer opinions on responses to inequity. Journal of Personality and Social Psychology, 37, 2253-2261.

Folger, R., Rosenfield, D., \& Robinson, T. (1983). Relative deprivation and procedural justifications. Journal of Personality and Social Psychology, 45, 268-273.

Folger, R., \& Skarlicki, D. P. (1998). A popcorn metaphor for employee aggression. In R. Griffin, A. O'Leary-Kelly, \& J. Collins (Eds.), Dysfunctional behavior in organizations: Volume 1. Violent behavior in organizations (pp. 43-82). Greenwich, CT: JAI Press.

Greenberg, J. (1986). Determinants of perceived fairness of performance evaluations. Journal of Applied Psychology, 71, 340-342.

Greenberg, J. (1987a). Reactions to procedural injustice in payment distributions: Do the ends justify the means? Journal of Applied Psychology, 72, 55-61.

Greenberg, J. (1987b). Using diaries to promote procedural justice in performance appraisals. Social Justice Research, 1, 219-234.

Greenberg, J. (1990). Organizational justice: Yesterday, today, and tomorrow. Journal of Management, 16, 399-432.

Greenberg, J. (1993). Stealing in the name of justice: Informational and interpersonal moderators of theft reactions to underpayment inequity. Organizational Behavior and Human Decision Processes, 54, 81-103.

Greenberg, J. (1994). Using socially fair treatment to promote acceptance of a work site smoking ban. Journal of Applied Psychology, 79, 288-297. 
Greenberg, J. (1997). A social influence model of employee theft: Beyond the fraud triangle. In R. J. Lewicki, R. J. Bies, \& B. H. Sheppard (Eds.), Research on negotiation in organizations (Vol. 6, pp. 29-52). Greenwich, CT: JAI Press.

Greenberg, J. (2000). Promote procedural justice to enhance acceptance of work outcomes. In E. A. Locke (Ed.), A handbook of principles of organizational behavior (pp. 181-195). Oxford, England: Blackwell.

Greenberg, J., \& Folger, R. (1983). Procedural justice, participation, and the fair process effect in groups and organizations. In P. B. Paulus (Ed.), Basic group processes (pp. 235-256). New York: Springer-Verlag.

Greenberg, J., \& Lind, E. A. (2000). The pursuit of organizational justice: From conceptualization to implication to application. In C. L. Cooper \& E. A. Locke (Eds.), I/O psychology: What we know about theory and practice (pp. 72-105). Oxford, England: Blackwell.

Hafer, C. L. (2000). Do innocent victims threaten the belief in a just world? Evidence from a modified Stroop task. Journal of Personality and Social Psychology, 79, 165-173.

Haidt, J. (2001). The emotional dog and its rational tail: A social intuitionist approach to moral judgment. Psychological Review, 108, 814-834.

Hare, R. M. (1981). Moral thinking: Its levels, method, and point. Oxford: Clarendon Press.

Hirschman, A. O. (1970). Exit, voice and loyalty: Responses to declines in firms, organizations, and states. Cambridge, MA: Harvard University Press.

Homans, G. C. (1961). Social behavior: Its elementary forms. New York: Harcourt, Brace, \& World.

Huo, Y. J., Smith, H. J., Tyler, T. R., \& Lind, E. A. (1996). Superordinate identification, subgroup identification, and justice concerns: Is separatism the problem; is assimilation the answer? Psychological Science, 7, 40-45.

Jasso, G. (1994). Assessing individual and group differences in the sense of justice: Framework and application to gender differences in the justice of earnings. Social Science Research, 23, 368-406.

Jasso, G. (1999). How much injustice is there in the world? Two new justice indexes. American Sociological Review, 64, 133-168.

Kahneman, D., \& Tversky, A. (1982). The simulation heuristic. In D. Kahneman, P. Slovic, \& A. Tversky (Eds.), Judgment under uncertainty: Heuristics and biases (pp. 201-208). New York: Cambridge University Press.

Kanfer, R., Sawyer, J., Earley, P. C., \& Lind, E. A. (1987). Fairness and participation in evaluation procedures: Effects on task attitudes and performance. Social Justice Research, 1, 235-249.

Konovsky, M., \& Folger, R. (1991, August). The effects of procedural and distributive justice on organizational citizenship behavior. Paper presented at the annual meeting of the Academy of Management, Miami Beach, FL.

Korsgaard, M. A., Schweiger, D. M., \& Sapienza, H. J. (1995). Building commitment, attachment, and trust in strategic decision-making teams: The role of procedural justice. Academy of Management Journal, 38, 60-84.

Landman, J. (1987). Regret and elation following action and inaction: Affective reactions to positive versus negative outcomes. Personality and Social Psychology Bulletin, 13, 524-536.

Lerner, M. J., \& Whitehead, L. A. (1980). Procedural justice viewed in the context of justice motive theory. In G. Mikula (Ed.), Justice and social interaction: Experimental and theoretical contributions from psychological research (pp. 219-256). Bern, Austria: Huber. 
Leventhal, G. S. (1980). What should be done with equity theory? New approaches to the study of fairness in social relationships. In K. J. Gergen, M. S. Greenberg, \& R. H. Willis (Eds.), Social exchange: Advances in theory and research (pp. 27-54). New York: Plenum.

Lind, E. A. (1990). Arbitrating high-stakes cases: An evaluation of court-annexed arbitration in a United States district court. Santa Monica, CA: Rand Corporation.

Lind, E. A. (2001). Fairness heuristic theory: Justice judgments as pivotal cognitions in organizational relations. In J. Greenberg \& R. Cropanzano (Eds.), Advances in organizational behavior (pp. 56-88). Stanford, CA: Stanford University Press.

Lind, E. A., Greenberg, J., Scott, K. S., \& Welchans, T. D. (2000). The winding road from employee to complainant: Situational and psychological determinants of wrongful termination claims. Administrative Science Quarterly, 45, 557-590.

Lind, E. A., Kanfer, R., \& Earley, P. C. (1990). Voice, control, and procedural justice: Instrumental and noninstrumental concerns in fairness judgments. Journal of Personality and Social Psychology, 59, 952-959.

Lind, E. A., Kulik, C. T., Ambrose, M., \& de Vera Park, M. V. (1993). Individual and corporate dispute resolution: Using procedural fairness as a decision heuristic. Administrative Science Quarterly, 38, 224-251.

Lind, E. A., Kurtz, S., Musante, L., Walker L., \& Thibaut, J. (1980). Procedure and outcome effects on reactions to adjudicated resolution of conflicts of interest. Journal of Personality and Social Psychology, 39, 643-653.

Lind, E. A., \& Tyler, T. R. (1988). The social psychology of procedural justice. New York: Plenum.

Lind, E. A., \& Van den Bos, K. (2002). When fairness works: Toward a general theory of uncertainty management. In B. M. Staw \& R. M. Kramer (Eds.), Research in organizational behavior (Vol, 24, pp. 181-223). Greenwich, CT: JAI Press.

McFarlin, D. B., \& Sweeney, P. D. (1992). Distributive and procedural justice as predictors of satisfaction with personal and organizational outcomes. Academy of Management Journal, 35, 626-637.

Messick, D. M., \& Sentis, K. (1983). Fairness, preference, and fairness biases. In D. M. Messick \& K. S. Cook (Eds.), Equity theory: Psychological and sociological perspectives (pp. 61-94). New York: Praeger.

Mikula, G., \& Wenzel, M. (2000). Justice and social conflict. International Journal of Psychology, 35, 126-135.

Moorman, R. H. (1991). Relationship between organizational justice and organizational citizenship behaviors: Do fairness perceptions influence employee citizenship? Journal of Applied Psychology, 76, 845-855.

Paternoster, R., Brame, R., Bachman, R., \& Sherman, L. W. (1997). Do fair procedures matter? The effect of procedural justice on spouse assault. Law and Society Review, 31, 163-204.

Peeters, G., \& Czapinski, J. (1990). Positive-negative asymmetry in evaluations: The distinction between affective and information negativity effects. In W. Stroebe \& M. Hewstone (Eds.), European review of social psychology (Vol. 1, pp. 33-60). Chichester, UK: Wiley.

Podsakoff, P. M., \& MacKenzie, S. B. (1993). Citizenship behavior and fairness in organizations: Issues and directions for future research. Employee Responsibilities and Rights Journal, 6, 235-247.

Rawls, J. (1971). A theory of justice. Oxford: Oxford University Press.

Rutte, C. G., \& Messick, D. M. (1995). An integrated model of perceived unfairness in organizations. Social Justice Research, 8, 239-261. 
Sabbagh, C., Dar, Y., \& Resh, N. (1994). The structure of social justice judgments: A facet approach. Social Psychology Quarterly, 57, 244-261.

Skitka, L. J. (2002). Do the means always justify the ends, or do the ends sometimes justify the means? A value protection model of justice. Personality and Social Psychology Bulletin, 28, 588-597.

Smith, H. J., \& Tyler, T. R. (1997). Choosing the right pond: The impact of group membership on self-esteem and group-oriented behavior. Journal of Experimental Social Psychology, 33, 146-170.

Smith, H. J., Tyler, T. R., Huo, Y. J., Ortiz, D. J., \& Lind, E. A. (1998). The self-relevant implications of the group-value model: Group-membership, self-worth and treatment quality. Journal of Experimental Social Psychology, 34, 470-493.

Steiner, D. D., Guirard, S., \& Baccino, T. (1999, May). Cognitive processing of procedural justice information: Application of the oculometer. Paper presented at the Annual Conference of the Society for Industrial/Organizational Psychology, Atlanta, GA.

Stouffer, S. A., Suchman, E. A., DeVinney, L. C., Star, S. A., \& Williams, R. M. (1949). The American soldier: Adjustment during Army life (Vol. 1). Princeton, NJ: Princeton University Press.

Sweeney, P. D., \& McFarlin, D. B. (1993). Workers' evaluations of the "ends" and the "means": An examination of four models of distributive and procedural justice. Organizational Behavior and Human Decision Processes, 54, 23-40.

Thibaut, J., \& Walker, L. (1975). Procedural justice: A psychological analysis. Hillsdale, NJ: Lawrence Erlbaum Associates.

Thibaut, J., \& Walker, L. (1978). A theory of procedure. California Law Review, 66, 541-566.

Tyler, T. R. (1984). The role of perceived injustice in defendants' evaluations of their courtroom experience. Law and Society Review, 18, 51-74.

Tyler, T. R. (1987). Conditions leading to value-expressive effects in judgments of procedural justice: A test of four models. Journal of Personality and Social Psychology, 52, 333-344.

Tyler, T. R. (1990). Why do people obey the law? Procedural justice, legitimacy, and compliance. New Haven, CT: Yale University Press.

Tyler, T. R. (1991). Using procedures to justify outcomes: Testing the viability of a procedural justice strategy for managing conflict and allocating resources in organizations. Basic and Applied Psychology, 12, 259-279.

Tyler, T. R. (1994). Psychological models of the justice motive: Antecedents of distributive and procedural justice. Journal of Personality and Social Psychology, 67, 850-863.

Tyler, T. R. (1997). The psychology of legitimacy: A relational perspective on voluntary deference to authorities. Personality and Social Psychology Review, 1, 323-345.

Tyler, T. R., \& Bies, R. J. (1990). Beyond formal procedures: The interpersonal context of procedural justice. In J. S. Caroll (Ed.), Applied social psychology and organizational settings (pp. 77-98). Hillsdale, NJ: Lawrence Erlbaum Associates.

Tyler, T. R., Boeckmann, R. J., Smith, H. J., \& Huo, Y. J. (1997). Social justice in a diverse society. Boulder, CO: Westview.

Tyler, T. R., \& Caine, A. (1981). The influence of outcomes and procedures on satisfaction with formal leaders. Journal of Personality and Social Psychology, 41, 642-655.

Tyler, T. R., \& DeGoey, P. (1995). Collective restraint in social dilemmas: Procedural justice and social identification effects on support for authorities. Journal of Personality and Social Psychology, 69, 482-497. 
Tyler, T. R., DeGoey, P., \& Smith, H. J. (1996). Understanding why the justice of group procedures matters: A test of the psychological dynamics of the group-value model. Journal of Personality and Social Psychology, 70, 913-930.

Tyler, T. R., \& Folger, R. (1980). Distributional and procedural aspects of satisfaction with citizen-police encounters. Basic and Applied Social Psychology, 1, 281-292.

Tyler, T. R., \& Lind, E. A. (1990). Intrinsic versus community-based justice models: When does group membership matter? Journal of Social Issues, 46, 83-94.

Tyler, T. R., \& Lind, E. A. (1992). A relational model of authority in groups. In M. P. Zanna (Ed.), Advances in experimental social psychology (Vol. 25, pp. 115-191). San Diego, CA: Academic Press.

Tyler, T. R., Rasinski, K. A., \& McGraw, K. M. (1985). The influence of perceived injustice on the endorsement of political leaders. Journal of Applied Social Psychology, 15, 700-725.

Van den Bos, K. (2001a). Uncertainty management: The influence of uncertainty salience on reactions to perceived procedural fairness. Journal of Personality and Social Psychology, 80, 931-941.

Van den Bos, K. (2001b). Fundamental research by means of laboratory experiments is essential for a better understanding of organizational justice. Journal of Vocational Behavior, 58, 254-259.

Van den Bos, K. (2001c). Fairness heuristic theory: Assessing the information to which people are reacting has a pivotal role in understanding organizational justice. In S. W. Gilliland, D. D. Steiner, \& D. P. Skarlicki (Eds.), Theoretical and cultural perspectives on organizational justice (pp. 63-84). Greenwich, CT: Information Age.

Van den Bos, K. (2001d). Reactions to perceived fairness: The impact of mortality salience and self-esteem on ratings of negative affect. Social Justice Research, 14, $1-23$.

Van den Bos, K. (2003). On the subjective quality of social justice: The role of affect as information in the psychology of justice judgments. Journal of Personality and Social Psychology, 85, 482-498.

Van den Bos, K., Heuven, E., Burger, E., \& Fernández van Veldhuizen, M. (in press). Uncertainty management after reorganizations: The ameliorative effect of outcome fairness on job uncertainty. International Review of Social Psychology.

Van den Bos, K., \& Lind, E. A. (2002). Uncertainty management by means of fairness judgments. In M. P. Zanna (Ed.), Advances in experimental social psychology (Vol. 34, pp. 1-60). San Diego, CA: Academic Press.

Van den Bos, K., Lind, E. A., Vermunt, R., \& Wilke, H. A. M. (1997). How do I judge my outcome when I do not know the outcome of others? The psychology of the fair process effect. Journal of Personality and Social Psychology, 72, 1034-1046.

Van den Bos, K., Lind, E. A., \& Wilke, H. A. M. (2001). The psychology of procedural and distributive justice viewed from the perspective of fairness heuristic theory. In R. Cropanzano (Ed.), Justice in the workplace: Volume 2-From theory to practice (pp. 49-66). Mahwah, NJ: Lawrence Erlbaum Associates.

Van den Bos, K., Maas, M., Waldring, I. E., \& Semin, G. R. (2003). Toward understanding the psychology of reactions to perceived fairness: The role of affect intensity. Social Justice Research, 16, 151-168.

Van den Bos, K., \& Miedema, J. (2000). Toward understanding why fairness matters: The influence of mortality salience on reactions to procedural fairness. Journal of Personality and Social Psychology, 79, 355-366.

Van den Bos, K., \& Spruijt, N. (2002). Appropriateness of decisions as a moderator of the psychology of voice. European Journal of Social Psychology, 32, 57-72. 
Van den Bos, K., \& Van Prooijen, J.-W. (2001). Referent cognitions theory: The role of closeness of reference points in the psychology of voice. Journal of Personality and Social Psychology, 81, 616-626.

Van den Bos, K., Van Schie, E. C. M., \& Colenberg, S. E. (2002). Parents' reactions to child day care organizations: The influence of perceptions of procedures and the role of organizations' trustworthiness. Social Justice Research, 15, 53-62.

Van den Bos, K., Vermunt, R., \& Wilke, H. A. M. (1996). The consistency rule and the voice effect: The influence of expectations on procedural fairness judgements and performance. European Journal of Social Psychology, 26, 411-428.

Van den Bos, K., Vermunt, R., \& Wilke, H. A. M. (1997). Procedural and distributive justice: What is fair depends more on what comes first than on what comes next. Journal of Personality and Social Psychology, 72, 95-104.

Van den Bos, K., Wilke, H. A. M., \& Lind, E. A. (1998). When do we need procedural fairness? The role of trust in authority. Journal of Personality and Social Psychology, $75,1449-1458$.

Van den Bos, K., Wilke, H. A. M., Lind, E. A., \& Vermunt, R. (1998). Evaluating outcomes by means of the fair process effect: Evidence for different processes in fairness and satisfaction judgments. Journal of Personality and Social Psychology, 74, 1493-1503.

Van Prooijen, J.-W., Van den Bos, K., \& Wilke, H. A. M. (2002). Procedural justice and status: Status salience as antecedent of the fair process effect. Journal of Personality and Social Psychology, 83, 1353-1361.

Van Prooijen, J.-W., Van den Bos, K., \& Wilke, H. A. M. (in press). The role of standing in the psychology of procedural justice: Toward theoretical integration. In W. Stroebe \& M. Hewstone (Eds.), European Review of Social Psychology, 14. Hove, UK: Psychology Press.

Vermunt, R., Wit, A., Van den Bos, K., \& Lind, A. (1996). The effect of inaccurate procedure on protest: The mediating role of perceived unfairness and situational self-esteem. Social Justice Research, 9, 109-119.

Walker, L., LaTour, S., Lind, E. A., \& Thibaut, J. (1974). Reactions of participants and observers to modes of adjudication. Journal of Applied Social Psychology, 4, 295-310.

Walker, L., Lind, E. A., \& Thibaut, J. (1979). The relation between procedural and distributive justice. Virginia Law Review, 65, 1401-1420.

Walster, E., Berscheid, E., \& Walster, G. W. (1973). New directions in equity research. Journal of Personality and Social Psychology, 25, 151-176.

Walster, E., Walster, G. W., \& Berscheid, E. (1978). Equity: Theory and research. Boston: Allyn \& Bacon.

Weiss, H. M., Suckow, K., \& Cropanzano, R. (1999). Effects of justice conditions on discrete emotions. Journal of Applied Psychology, 84, 786-794.

White, R. W. (1959). Motivation reconsidered: The concept of competence. Psychological Review, 66, 297-333.

Zeelenberg, M., Van den Bos, K., Van Dijk, E., \& Pieters, R. G. M. (2002). The inaction effect in the psychology of regret. Journal of Personality and Social Psychology, 82, 314-327. 